\title{
Airway management considerations for appendectomy
}

\author{
Joaquin Fabregat-López, MD · Tim Cook, FRCA
}

Received: 17 January 2010/ Accepted: 10 February 2010/Published online: 26 February 2010

(C) Canadian Anesthesiologists' Society 2010

\section{To the Editor,}

Recently, Istvan et al. reported ${ }^{1}$ a case review of airway management for appendectomies from the Hôpital Maisonneuve-Rosemont, Montreal, Quebec, Canada. Rapid sequence induction (RSI) with tracheal intubation was used for more than $80 \%$ of 250 emergency appendectomies, with transient blood pressure changes (35\%) and intubation difficulty $(1.2 \%)$ being the only complications. Istvan et al. concluded that it is not necessary to recommend a change in practice and implied both efficacy and safety of RSI for appendectomies.

There is some debate regarding airway management for emergency appendectomies. Traditionally, authors recommend tracheal intubation and RSI because of concerns over pulmonary aspiration. In practice, there are likely wide variations in airway management, e.g., in Istvan et al.'s series, $19 \%$ of the patients did not receive RSI and two patients in their pilot phase underwent laryngeal mask airway $\left(\mathrm{LMA}^{\mathrm{TM}}\right.$; LMA North America, San Diego, CA, USA) anesthesia. Recently, we published a series of 102 patients who presented for emergency appendectomies in a one-year period (2007) and were managed with a ProSeal laryngeal mask airway (PLMA ${ }^{\mathrm{TM}}$; LMA North America, San Diego, CA, USA). ${ }^{2}$

There are clear advantages to avoiding intubation where it is not necessary; the only difficulty is defining those circumstances. Although it has been assumed that the

J. Fabregat-López, MD ( $\square)$

Department of Anaesthesia, University Hospital Rosell,

Cartagena, Murcia, Spain

e-mail: kinoyo@hotmail.com

T. Cook, FRCA

Royal United Hospital, CombePark, Bath, UK combination of abdominal surgery and urgency must predispose to passive regurgitation, as summarized by Istvan et al., the incidence appears to be low. Prior to our study, we could find no data on the incidence of regurgitation in this population. Review of the literature suggests that the pulmonary aspiration in the perioperative period is infrequent. ${ }^{3}$ Thus, perhaps there is a discrepancy between the risk of regurgitation during induction and the number of patients treated as at risk of aspiration. In our study, all patients were managed effectively and safely throughout surgery, and, while we acknowledge readily that such a small study cannot confirm safety, the absence of complications is notable. As a small first step, at least our results are reassuring and provide a starting point. $^{2}$

Recent advances in supraglottic airway device (SAD) technology not only make some devices easy to use, they also increase their level of protection against aspiration. ${ }^{4}$ If a SAD is to be considered for such use in a higher risk patient, we would argue that it is logical to use a device that has a good airway seal, design features that reduce the risk of aspiration, and a proven track record. The PLMA is foremost among such devices. Inevitably, testing the limits of safe use of equipment is very difficult, as studies designed to explore boundaries are likely to have intrinsic risk. However, failure to consider such possibilities has its own risk. While some might consider even selective use of a PLMA for appendectomies as inappropriate, it is notable that others might equally point to the science of RSI as unproven and associated with increased risk. ${ }^{5}$ As ever, more high quality research is required in this difficult area.

Conflicts of interest Dr. Tim Cook has been paid by Intavent Orthofix and the LMA Company (manufacturers of laryngeal mask airways, including the ProSeal LMA) for lecturing. He has no financial interest in these or any anesthetic company equipment. 


\section{References}

1. Istvan J, Belliveau $M$, Donati $F$. Rapid sequence induction for appendectomies: a retrospective case-review analysis. Can J Anesth 2010; DOI 10.1007/s12630-009-9260-1.

2. Fabregat-Lopez J, Garcia-Rojo B, Cook TM. A case series of the use of the ProSeal laryngeal mask airway in emergency lower abdominal surgery. Anaesthesia 2008; 63: 967-71.

3. Warner MA, Warner ME, Weber JG. Clinical significance of pulmonary aspiration during the perioperative period. Anesthesiology 1993; 78: 56-62.

4. Cook TM, Lee G, Nolan JP. The ProSeal ${ }^{\mathrm{TM}}$ laryngeal mask airway: a review of the literature. Can J Anesth 2005; 52: 739-60.

5. Neilipovitz DT, Crosby ET. No evidence for decreased incidence of aspiration after rapid sequence induction. Can J Anesth 2007; 54: $748-64$.

\section{Reply}

In the Letter related to our article entitled "Rapid sequence induction for appendectomies: a retrospective case-review analysis", 1 where tracheal intubation was performed in all patients, Dr. Fabregat-López and Dr. Cook refer to the successful use of the ProSeal laryngeal mask airway (PLMA) in a recent series of 102 appendectomies. ${ }^{2} \mathrm{We}$ agree with their assertion that "such a small study cannot confirm safety". The number of patients needed to detect a rare event in a study is roughly equivalent to three times the incidence. ${ }^{3}$ Therefore, this study was powered to detect an event that had and incidence of 1/34 (approximately $3 \%$ ). Since aspiration in appendectomies seems to occur at a much lower incidence, ${ }^{4}$ it is not surprising that it was not observed.

In addition, Fabregat-López et al.'s ${ }^{2}$ study did not include many patients who presented with an increased risk of aspiration. For example, patients with an anticipated difficult intubation, obesity, esophageal reflux, and severe pain were excluded, as were those who had not fasted for at least eight hours. All cases were reviewed in our retrospective study ${ }^{1}$. The design of the newer supraglottic airway devices has been improved; as a result, their effectiveness as barriers against regurgitation is probably better than in the past. However, the risk of aspiration is greatest when the airway is unprotected at induction and emergence, thus, priority should be given to the rapid insertion of the airway device at induction and its removal only when the patient is fully awake. Thus, if it could be shown that a PLMA is effective against aspiration, it would appear logical to recommend that its insertion be preceded by a rapid sequence induction (RSI).

Therefore, based on the study by Fabregat-López et al., ${ }^{2}$ our conclusion is that PLMA can be used successfully for appendectomies in selected cases. More data are required to conclude that a PLMA is safe as a first line airway management device in this setting, and RSI appears prudent if PLMAs are shown to protect against aspiration. Therefore, until more evidence becomes available, we continue to recommend RSI with tracheal intubation for appendectomies as primary airway management.

Funding sources None.

Disclosure of conflicts of interest for all authors None.

\section{References}

1. Istvan J, Belliveau M, Donati $F$. Rapid sequence induction for appendectomies: a retrospective case-review analysis. Can J Anesth 2010; DOI 10.1007/s12630-009-9260-1.

2. Fabregat-Lopez J, Garcia-Rojo B, Cook TM. A case series of the use of the ProSeal laryngeal mask airway in emergency lower abdominal surgery. Anaesthesia 2008; 63: 967-71.

3. Sackett DL, Haynes RB, Gent $M$, Taylor DW. Compliance. In: Inman WH, editor. Monitoring for Drug Safety. Lancaster, UK: MTP Press; 1980.

4. Neilipovitz DT, Crosby ET. No evidence for decreased incidence of aspiration after rapid sequence induction. Can J Anesth 2007; 54: 748-64.

Juraj Istvan, MD

McGill University, Montreal, QC, Canada

François Donati, MD, $\mathrm{PhD}$

Hôpital Maisonneuve-Rosemont and Université de Montréal,

Montréal, QC, Canada 